\title{
Radiological and dermatological findings in two patients suffering from early yaws in Indonesia
}

\author{
H J H Engelkens, A Z Ginai, Jubianto Judanarso, Chaidir Kasim, J van der Stek, J J van der
}

Sluis, E Stolz

\begin{abstract}
Two children suffering from early yaws in Indonesia are presented. Apart from skin lesions and a positive treponemal serology in both patients, involvement of tubular bones, particularly of the hands, was revealed by radiological examination. In one patient involvement of a distal phalanx was remarkable. Early diagnosis and treatment of yaws is important since a delay in treatment may result in severe and irreversible bone deformities of the late stage of the disease. This report illustrates that radiological changes, although rare, can still be detected in the early stage of yaws in areas where yaws is resurgent nowadays.
\end{abstract}

\section{Introduction}

The high incidence of the endemic treponematoses in countries in the tropical zone around the globe has been greatly reduced as a result of successful mass campaigns (World Health Organisation and United Nations Children's Fund) in the 1950s and 1960s. Complete eradication has, however, not been accomplished and a resurgence is now reported. Yaws, a chronic infectious disease caused by Treponema pallidum subspecies pertenue ( $T$. pertenue), is mainly found in humid tropical regions of the world, the socalled areas "where the highways end". "Yaws is transmitted by non-venereal bodily contacts. Children especially under the age of 15 years are affected.

The recognition and treatment of early yaws is of paramount importance as bone changes at this stage

Department of Dermatology and Venereology, University Hospital Rotterdam-Dijkzigt and Erasmus University Rotterdam, The Netherlands

H J H Engelkens, J van der Stek, J J van der Sluis, E Stolz The Department of Radiology, University Hospital Rotterdam-Dijkzigt, The Netherlands

A Z Ginai

The Department of Dermatology and Venereology, Medical Faculty, University of Indonesia, Jakarta, Indonesia

Jubianto Judanarso

The Department of Radiology, Medical Faculty, Andalas University, Padang, Indonesia

Chaidir Kasim are still reversible. In the late stage of the disease bone involvement can result in mutilating and often irreversible disabilities. Radiographical descriptions of bone abnormalities in yaws have rarely been published during the last 25 years..$^{2-4}$

This report presents the observations in two patients with yaws in Indonesia, both complaining of painful fingers.

\section{CASE REPORTS}

Patient $A$

On 18 November 1988, a girl aged 15 years, born in Indonesia, was examined in Sumatera Barat. Approximately one year earlier she had noticed a skin lesion on the right foot sole, which left a scar after healing. She complained of considerable pain in the left and right middle fingers. In her residential area many cases of infectious yaws had been noted by the Centre for Disease Control in Padang. Physical examination revealed a tissue-paper scar on the right heel (fig 1) and hyperkeratosis of the foot soles. A tender fusiform swelling of some of the fingers was also obvious (fig 2). Serological findings were: VDRL + +, TPHA $2+$ and FTA-ABS $3+$.

Radiological examination of the hands and lower legs revealed involvement of the third proximal phalanx of both hands. Spindle-shaped soft tissue swellings were visible around the phalanges. The bony changes consisted of increased density and sclerosis involving the shaft of the phalanx. A dense

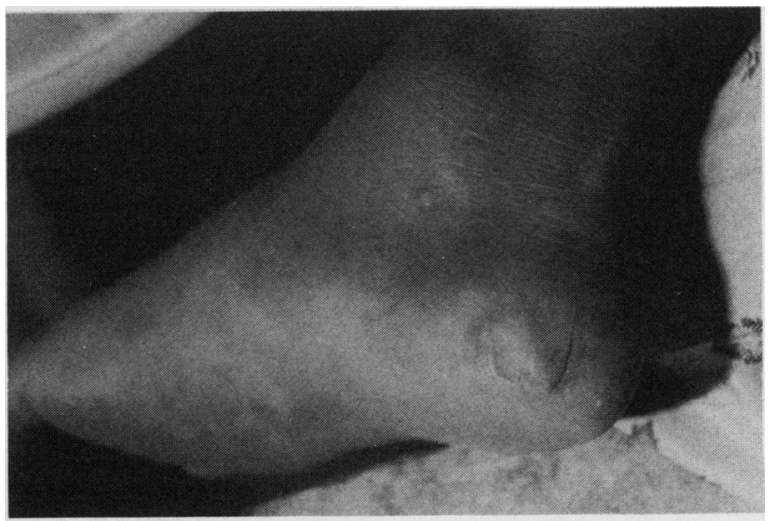

Figure 1 Tissue-paper scar on right heel in patient $A$. 

organised periosteal reaction around this region was also visible, with some thickening of the cortex and

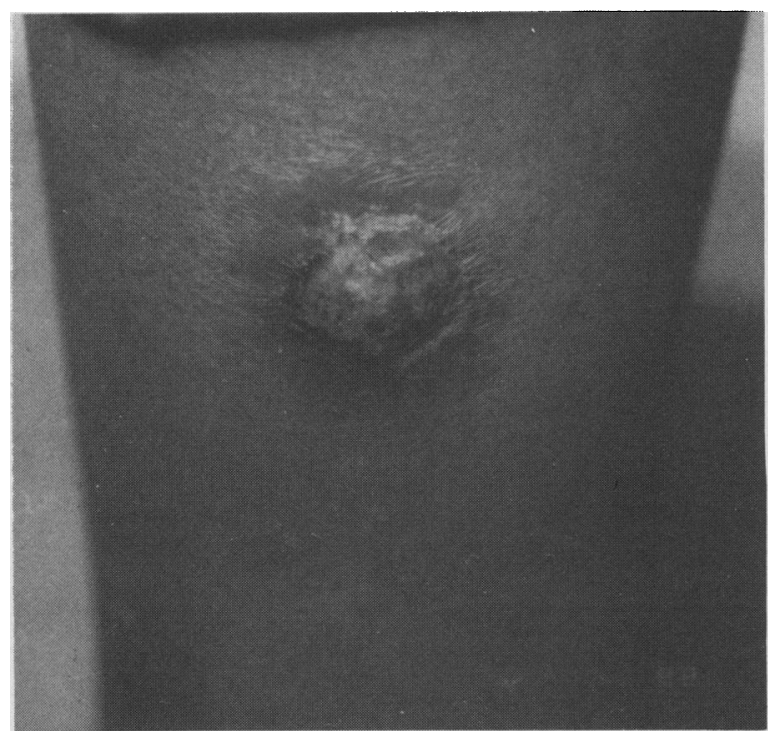

Figure 4 A crustopapillomatous lesion surrounded by wrinkled skin on the left thigh of patient $B$. increase in width of the phalanx (fig 3). The radiographs of the lower legs showed some soft tissue swelling around the right ankle. A periosteal reaction was noted around the medial malleolus and the distal $7-8 \mathrm{~cm}$ of the right fibula showed increase in width compared to the left side.

Early yaws was diagnosed on clinical, serological and epidemiological grounds. In addition, radiological examination showed bone abnormalities which are associated with this stage of yaws. Benzathine benzylpenicillin (Penidural ${ }^{\mathrm{R}}, 1.8$ million units) was injected intramuscularly. Unfortunately it was not possible to trace her family and contacts for prophylactic therapy.

\section{Patient $B$}

The second patient was a 10 year old boy born in Indonesia, examined in Sumatera Barat on 24 November 1988. He had had a skin lesion on the left thigh for the preceding two months. Examination revealed a solitary nummular crustopapillomatous lesion, $2 \mathrm{~cm}$ in diameter, surrounded by wrinkled skin on the left thigh (fig 4). A tender, fusiform swelling of the right middle finger and left index finger was noticed (fig 5 ). Serological findings were: VDRL + +, TPHA $2+$ and FTA-ABS $3+$. Dark-

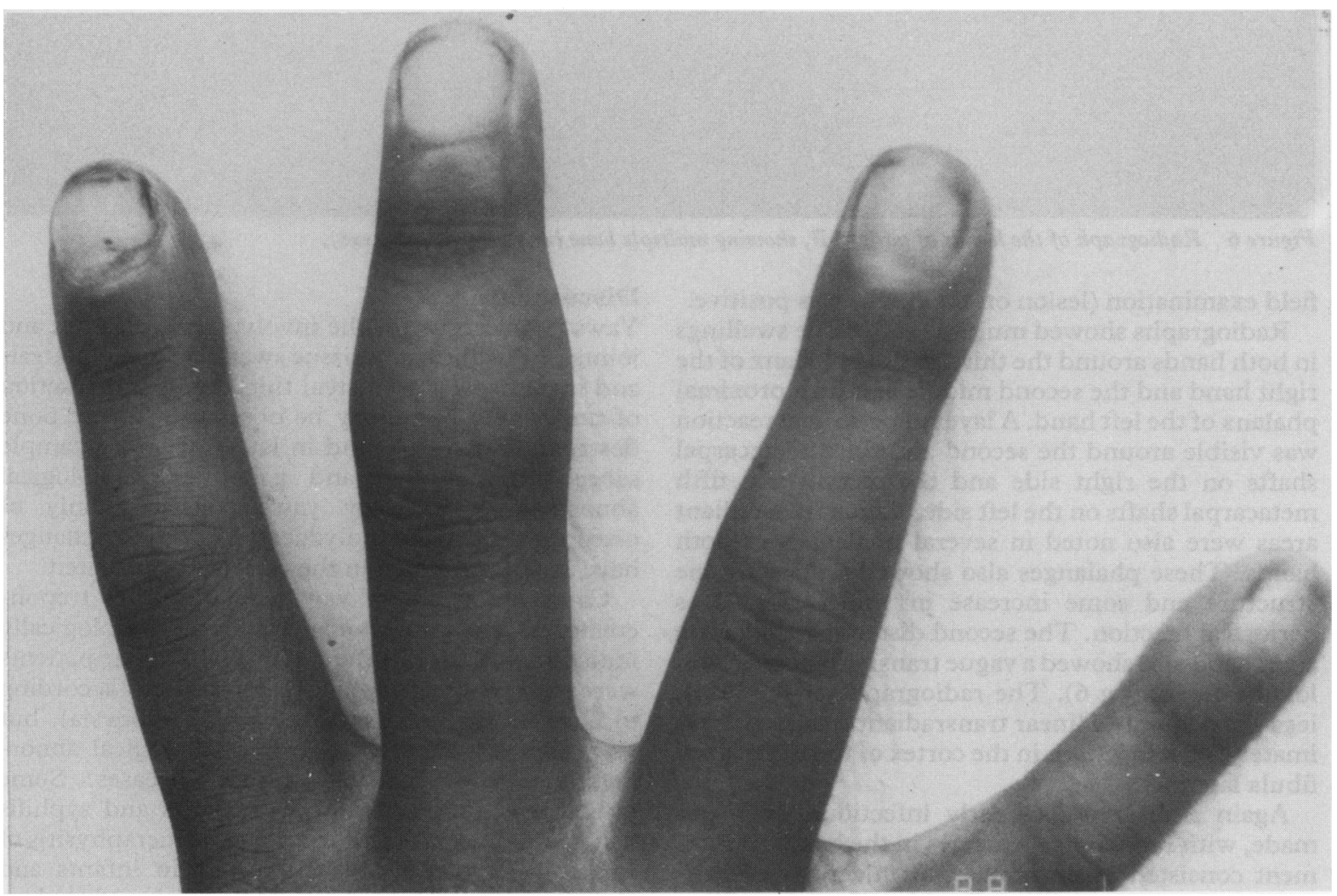

Figure 5 Swelling of right middle finger in patient $B$. 


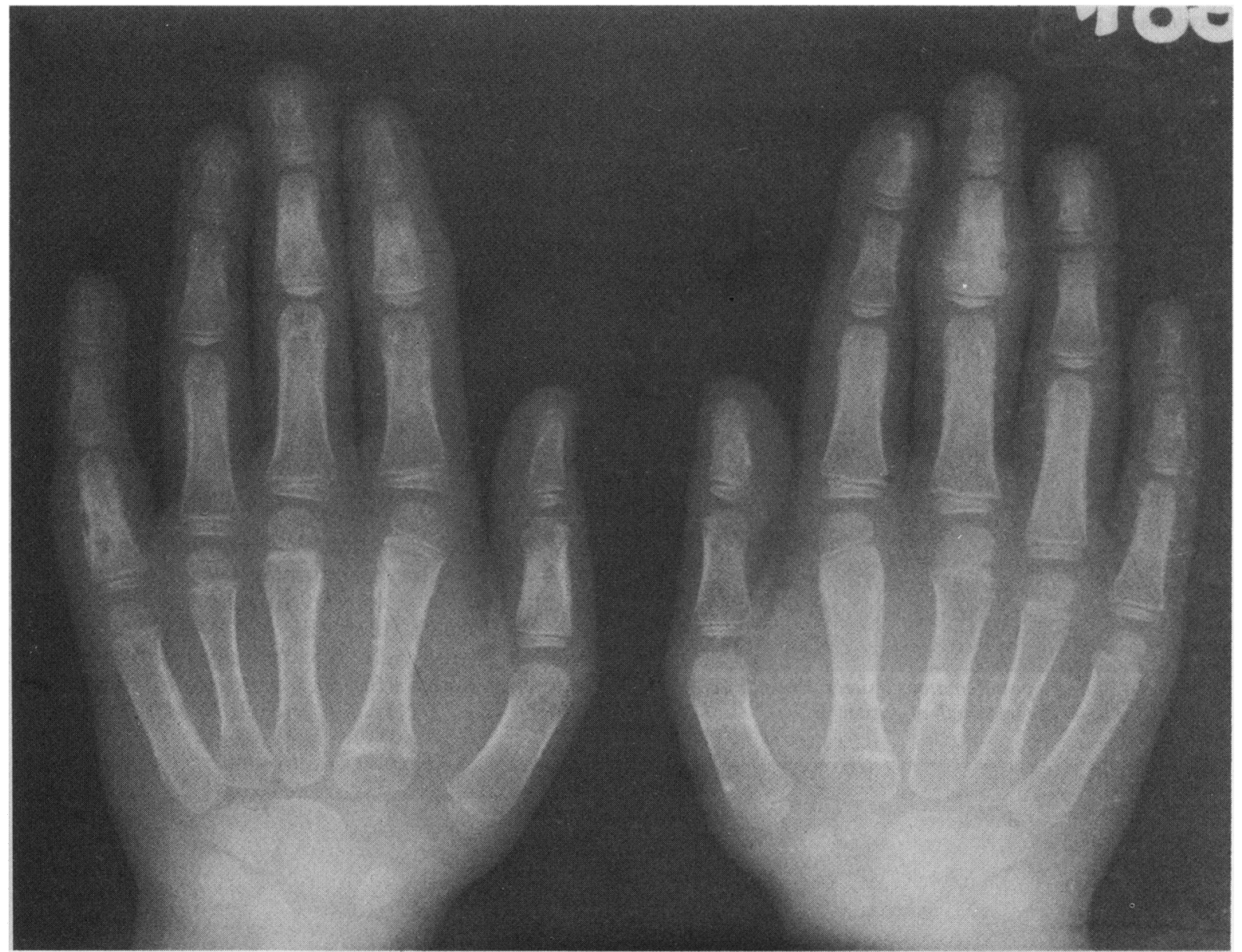

Figure 6 Radiograph of the hands of patient B, showing multiple bone involvement (see text).

field examination (lesion on the thigh) was positive.

Radiographs showed multiple soft tissue swellings in both hands around the third middle phalanx of the right hand and the second middle and fifth proximal phalanx of the left hand. A layer of periosteal reaction was visible around the second and third metacarpal shafts on the right side and the second and fifth metacarpal shafts on the left side. Vague transradiant areas were also noted in several phalanges of both hands. These phalanges also showed a denser bone structure and some increase in width as well as periosteal reaction. The second distal phalanx of the right hand also showed a vague transradiant area with loss of cortex (fig 6). The radiographs of the lower legs showed only a linear transradiant lesion approximately $2 \mathrm{~cm}$ in length in the cortex of the right distal fibula laterally.

Again a diagnosis of early infectious yaws was made, with radiological changes in the hands. Treatment consisted of intramuscular injections of benzathine benzylpenicillin (Penidural ${ }^{R}, 1.8$ million units). The contacts were traced and injected with benzathine benzylpenicillin $\left(\right.$ Penidural $^{\mathbb{R}}$ ).

\section{Discussion}

Yaws is notorious for the involvement of bones and joints. ${ }^{5-8}$ Fusiform soft tissue swellings of metatarsals and metacarpals, periosteal thickening and reaction of underlying bone may be observed. Severe bone destruction can be found in late yaws: for example sabre tibia, gondou and gangosa. ${ }^{1}$ Radiological abnormalities in early yaws consist mainly of osteoperiostitis and polydactylitis. These changes have also been shown in the two cases presented.

Causative agents of yaws and the other treponematoses are morphologically and serologically indistinguishable. In the regions where our patients were seen venereal syphilis is not present (according to Centres for Disease Control in Indonesia), but yaws is being reported again. ${ }^{9}$ Radiological abnormalities are important in both diseases. Some radiological differences between yaws and syphilis have been described, for example the metaphysitis of congenital syphilis does not occur in infants and children infected with yaws. Deformities of phalanges are said to be more common in yaws than in syphilis. $^{7}$ 
This article describes radiographic changes in two patients with early yaws. Proximal and middle phalanges as well as the metacarpals were involved. We noticed involvement of a distal phalanx in the second patient, which is an extremely rare finding. ${ }^{710}$ Plain radiographs are usually sufficient to define bone abnormalities in patients presenting with the clinical picture of the early stage of yaws. Several authors have suggested that bone scanning can show syphilitic bone lesions not yet visible on plain radiographs. ${ }^{11-13}$ Bone scanning may well be helpful in gaining a deeper insight into the extent of bone involvement in yaws, but further work in this direction would be necessary to define its value.

Recognition of the disease in the early stage and institution of antibiotic therapy for the patient as well as the contacts could help to save patients from the crippling and often irreversible deformities of the late stage of yaws and halt the spread of the disease.

We thank CDC Jakarta and CDC Padang in Indonesia, the patients who gave permission for examination, the medical personnel of the Health Centres involved, The Finsen Foundation, Rotterdam, and Gist-Brocades, Delft, The Netherlands for supply of penicillin. We would like to express our gratitude to G T Noordhoek, RIVM Bilthoven, The Netherlands for her kind help, and to T Rijsdijk for reproduction of the radiographs.
1 Perine PL, Hopkins DR, Niemel PLA, St. John RK, Causse G, Antal GM: Handbook of Endemic Treponematoses: Yaws, Endemic Syphilis, and Pinta. World Health Organisation, Geneva, 1984.

2 Lanigan-O'Keeffe FM, Holmes JG, Hill D. Infectious and active yaws in a Midland city. Br J Dermatol 1967;79:325-30.

3 Fluker JL, Boulton Hewitt A. Late yaws. $\mathrm{Br} J$ Venereal Dis 1970;46:264.

4 Hany El Tonsy M, Abdul Gaffoor PM, Benhawi M, Davidson JC. Late yaws: a case report. Sex Transm Dis 1982;9:205-7.

5 Patton JT. Bone and joint infection. In: Grainger RG, Allison DJ, eds. Diagnostic Radiology, 1st edn, Vol 2. Edinburgh: Churchill Livingstone, 1986;1360-1.

6 Hackett CJ. Bone Lesions of Yaws in Uganda. Oxford: Blackwell Scientific Publications, 1951.

7 Murray RO, Jacobson HG, Stoker DJ. Infections. In: Murray RO, Jacobson HG, Stoker DJ, eds. The Radiology of Skeletal Disorders, 3rd ed, Vol. 1. Edinburgh: Churchill Livingstone, 1990;319-21.

8 King A, Nicol C, Rodin P. Yaws; endemic syphilis; bejel; pinta. In: King A, Nicol C, Rodin P, eds. Venereal Diseases, 4th edn. London: Baillière Tindall, 1980;333-45.

9 Sosroamidjojo S, Rai K, Suesen N. Yaws in Indonesia. Southeast Asian J Trop Med Publ Health 1986;17(suppl):19-34.

10 Resnick D, Niwayama G. Osteomyelitis, septic arthritis, and soft tissue infection: the organisms. In: Resnick $D$, Niwayama $G$, eds. Diagnosis of Bone and Joint Disorders, 2nd ed, Vol 4. Philadelphia: WB Saunders Company, 1988;2700-1.

11 Ollé-Goig JE, Barrio JL, Gurgui M, Mildvan D. Bone invasion in secondary syphilis: case reports. Genitourin Med 1988;64:198-201.

12 Davidson F, Bruckner FE. Bone invasion in secondary syphilis (letter). Genitourin Med 1989;65:60.

13 Cronin EB, Williams WH, Tow DE. Radionuclide imaging in a case of tertiary syphilis involving the liver and bones. $J$ Nucl Med 1987;28:1047-51.

Address for correspondence: Prof Dr E Stolz, Department of Dermatology and Venereology, University Hospital RotterdamDijkzigt, Dr Molewaterplein 40, 3015 GD Rotterdam, The Netherlands

Accepted 24 April 1990 